\title{
CAMBIOS EN EL TRABAJO, COMPORTAMIENTO DE EMPRESARIOS Y SINDICATOS EN GRAN BRETAÑA DURANTE LA UULTIMA DÉCADA
}

\author{
Michael Terry
}

\section{INTRODUCCION}

1979 fue un año récord para las relaciones industriales británicas debido a que en ese año más trabajadores que nunca antes (más de cuatro millones y medio) se vieron envueltos en una huelga que llevó a una mayor pérdida de días de trabajo que en cualquiet af̃o anterior (más de 29 millones). La causa principal de este alto nivel de actividad huelguista fue una revuelta de los trabajadores de los servicios públicos, muchos de los cuales estaban mal pagados, contra los intentos del gobierno laborista de imponer un tetraso en el pago de los aumentos. La reacción pública a estas huelgas, y a la considerable desorganización que causaron, fueron vistas por algunos observadores como uno de los factores importantes que ayudaron a la victoria de Margaret Thatcher y al Partido Conservador en las elecciones de 1979.

Los setenta son ampliamente considerados como la década en la que los sindicatos consolidaron su posición como fuerza política e industrial; y fue entonces cuando empresarios y gobiernos se convencieron de que debian incluir a los sindicatos en todos los aspectos de la gestión económica a través del desarrollo de formas de regulaciones bipartitas o tripartitas de la industria y la economía.

Afiliación sindical y negociación colectiva se ampliaron en el sector de la industria privada, gracias también a que una legislación adecuada apoyó a los sindicatos entre 1974 y 1979. En el sector público se aplicó a un amplio volumen de trabajadores el modelo del "buen empresario», basado en el reconocimiento de los sindicatos y la disposición a contar con ellos. A muchos 
les pareció que esas tendencias iban a continuar; sin embargo, los 10 años que han seguido a 1979 han supuesto cambios radicales en casi todos los aspectos de las telaciones industriales; podríamos decir que han tenido lugar cambios impensables a finales de los setenta. Este artículo presenta una visión global tanto de lo que ha cambiado como de lo que permanece en el sistema de relaciones industriales en esta última década, identifica algunas tazones de tales fenómenos y sugiere ciertas implicaciones pata el futuro.

\section{CAMBIOS EN EL CONTEXTO}

DE LAS RELACIONES INDUSTRIALES

\section{El MERCADO de trabajo}

\section{TABLA 1}

Empleo por sectores en el Reino Unido, 1954-1987.

(Porcentaje del empleo total)

\begin{tabular}{|c|c|c|c|c|}
\hline Sector & 1954 & 1975 & 1980 & 1987 \\
\hline Primatic y servicios (a) & 10,6 & 5,5 & 5,3 & 4,2 \\
\hline Manufacturas ................... & 34,7 & 30,6 & 28,0 & 21,5 \\
\hline 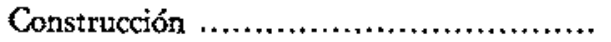 & 6,1 & 6,5 & 6,4 & 6,3 \\
\hline Distribución, transporte y comunicaciones & 24,7 & 24,9 & 26,1 & 27,1 \\
\hline Negocios y servicios varios.$\ldots \ldots \ldots \ldots \ldots \ldots$ & 9,1 & 12,8 & 14,7 & 20,2 \\
\hline Servicios auxiliates (b) .............. & 14,9 & 19,6 & 19,6 & 20,7 \\
\hline Economía total ................................. & 100,0 & 100,0 & 100,0 & 100,0 \\
\hline Sector público $\ldots \ldots \ldots \ldots \ldots \ldots$ & 24,3 & 29,0 & 29,2 & 25,6 \\
\hline
\end{tabular}

FUENTES: Datos del Institute for Employment Research, Review of the Economy and Employment (Coventry IER, University of Warwick, 1987).

Los datos para la categoría del sector público de 1954 y 1975 son de A. W, J. Thomson y P. B. Beaumont, Public Sector Bargaininy (Farnborough, Saxon House 1978), 115; Ios datos de 1980 y 1987 son de Economic Trends, numero 410 (diciembre 1987), 98-107.

NOTaS: (a) Agricultura, silvicultura y pesca, minas y canteras, gas, electricidad y agua.

(b) Servicios médicos y dentales, organizaciones religiosas, servicio doméstico privado y gobiernos nacional y locales.

Durante los años ochenta se aceleraron varias tendencias de cambio a largo plazo en la composición y distribución de la fuerza de trabajo. La tendencia sectorial más notable fue el dramático descenso del empleo en la manufactura, ya que sólo entre 1980 y 1982 desaparecieron un million y medio de puestos de trabajo. En 1987 las industrias manufactureras sólo 
empleaban un poco más del 20 por ciento de la fuerza laboral activa. Se crearon cantidades significativas de puestos de trabajo en el sector de servicios privados, que en 1987 también enpleaba al 20 por ciento de los trabajadores. También estaban ampliamente representados en este crecimiento el sector de la venta al por menor, el sector fnanciero y los hoteles y empresas de alimentación.

El cambio del empleo del sector secundario al tetciatio, común a todas las economías industriales, parece haber sido particularmente marcado en Gran Bretaña. También ha habido cambios en cuanto a la composición por sexos de la población activa, que aparecen ligados a los mencionados anteriormente (en 1987 las mujeres constituían más del 45 por ciento de la población activa) y en la proporción de los trabajadores a tiempo parcial (en 1987 el 24 por ciento de la fuerza de trabajo, mujeres en su mayoría, trabajaban a tiempo parcial, es decir, unas 30 horas a la semana o menos). A pesar de esta «feminización» de la fuerza de trabajo, persiste una extendida segregación ocupacional entre trabajos «femeninos» y «masculinos», y las mujeres permanecen ampliamente excluidas de los niveles superiores en muchos trabajos.

Una nueva característica, digna de mención, ha sido el aumento del nú. mero de personas empleadas en trabajos creados con fondos del gobierno y planes de formación. Se estimó que en 1988 alrededor de 600.000 personas, principalmente jóvenes y parados de larga duración, tomaban parte en programas de formación de un año de duración. El componente de formación de estos programas ha sido considerado por muchos --incliyendo numerosos empresarios- insuficiente para satisfacer las necesidades cambiantes de los años ochenta. Los sindicatos han criticado los programas por los mismos motivos, alegando que se han puesto en práctica como medio para obtener mano de obra barata.

El empleo se ha trasladado geográficamente de las tradicionales áreas industriales del norte y el centro de Inglaterra y Escocia a Londres y al sureste. Las grandes industrias manufactureras, y las electrónicas de alta tecnologia, por ejemplo, han situado sus nuevas plantas en áteas rurales alejadas de las zonas del país donde tradicionalmente se ubicaban.

La innovación tecnológica ha reducido el tamaño de muchas fábricas y ha contribuido a un constante aumento en la propotción de empleados de «cuello blanco», proporcionando al mismo tiempo a los empresarios los medios y la motivación para romper antiguas demarcaciones entre categorías ocupacionales, así como para ampliar las divisiones entre trabajo manual y no manual, especialmente en industrias tales como la mecánica y la imprenta.

Estos factores, considerados junto con otros elementos, tales como el aparente aumento de la subcontratación y otros mecanismos utilizados para 
«externalizar» las telaciones de empleo, han llevado a muchos comentaristas a aducir que estamos observando una ruptura radical e irreversible en la naturaleza y futuro del trabajo. De hecho, términos como "posindustrial» y "posfordista» se usan cada vez más para indicar los importantes cambios habidos en los mercados interno y externo de trabajo, relacionados con la reestructuración de la industria manufacturera.

El concepto central es el de «flexibilidad» del trabajo vinculado a estra. tegias de producción de «especialización flexible» dirigidas a satisfacer, según se afirma, las nuevas demandas del cliente. El «trabajador flexible» dentro de la fábrica, capaz de cambiar fácilmente de un trabajo a otro, desplegando un amplio abanico de técnicas o competencias en la tarea, es el objetivo de muchas empresas.

Fuera de la fábrica, el uso de mano de obra subcontratada y de los que trabajan en casa proporciona a las empresas otra fuente de flexibilidad, que puede ser ampliada o reducida según la demanda del producto. Dicho de manera sencilla, ése es el modelo que muchos ven en la teestructuración del mercado de trabajo de los años ochenta. Sin embargo, durante estos último años se ha criticado duzamente la precisión de este análisis por autores (MacInnes, 1987; Pollert, 1987) que argumentan que la investigación no nos proporciona evidencia de ningún cambio estructural importante. Según MacInnes, el rasgo distintivo del mercado de trabajo británico ha sido su relativa estabilidad en conjunto.

Los críticos del «modelo» flexible no niegan que ha habido cambios. Hay una clata evidencia de una tendencia a la «multiespecialización» entre trabajadores de oficios tradicionales, tales como electricistas y mecánicos. A menudo se requiere a los trabajadores de producción que efectúen una serie de tareas de mantenimiento que no habrían hecho hace diez años. En las oficinas, la nueva tecnología está teniendo una profunda repercusión, segmentando aún más los mercados de trabajo de banca, por ejemplo, de tal manera que teduce las opottunidades de ascenso de la mujer. La revolución tecnológica en las imprentas ha transfotmado la naturaleza del trabajo en esa industria eliminando ocupaciones enteras y en algunos casos a los sindi. catos con ellas. Aquellos críticos insisten en que no han habido cambios cualitativos en la otanización del trabajo, sino sencillamente una continuación de las tendencias ya conocidas, aceleradas por la severidad de la crisis de últimos de los años setenta.

Los ochenta también han visto cambios relevantes relacionados con los salarios. Se ha invertido la lenta tendencia que acortaba las diferencias establecidas a través de varias décadas y los relativamente mejor pagados han visto aumentar sus ganancias tanto absoluta como relativamente. Ha aumentado la diferencia entre administrativos y obreros. Por otra parte, el número 
de empleados definidos como peor pagados ha aumentado, tendencia asociada en parte con el incremento del empleo a tiempo parcial. En 1979, 7,8 millones de trabajadores aduitos estaban por debajo del «umbral de dignidad» de la CEE; en 1987 este númeto había aumentado a 9,4 millones. Algunos analistas temen que estas cifras puedan aumentar aún más cuando el gobierno llegue a abolir los Consejos de Salarios, organismos que pueden fijar la paga minima estatutaria y las condiciones laborales para varios de los sectores peor pagados Ya se han abolido para los trabajadores menores de 18 años. Finalmente, también se han interrumpido los movimientos graduales hacia la paga igualitaria entre hombres y mujeres, con la paga de estas últimas estabilizada en más o menos dos tercios que la del hombre.

Una nueva imagen emerge de la fuerza de trabajo británica, que consiste, por una parte, en una mayoría relativamente estable y cada vez mejor pagada; y, pot otra parte, en una creciente minoría insegura y mal pagada, principalmente mujeres y trabajadores de las minorías étnicas. Estas personas, a quienes un líder sindical ha liamado "los nuevos desposeídos», no están protegidos ni por los sindicatos ni por la legislación (véase más adelante).

\section{La Ley deL Trabajo}

Durante los años setenta se ha corregido gradualmente la tradicional abstención legislativa frente a las relaciones industriales por medio de una serie de leyes que intentaban fortalecer la negociación colectiva y proporcionar un marco de protecciones a los trabajadores individuales, que cubriera temas no tratados a fondo en la negociación colectiva. Estas protecciones incluian un fortalecimiento de la protección contra el despido injusto, pro. tecciones contra la discriminación por causas de raza o sexo, y una serie de derechos sobre salud y seguridad. El enfoque legislativo se basaba en la opinión, compartida por los gobiernos de ambos partidos políticos desde 1945 , de que la negociación colectiva era, a pesar de los problemas ocasionales, el medio más eficaz para la regulación de las relaciones industriales; sin embargo, en los años setenta hubo ternas importantes que no consiguió abordar.

Desde 1979 , esta situación ha cambiado significativamente con la elección de un gobietno que generalmente concibe la negociación colectiva y los sindicatos como obstáculos para un eficaz funcionamiento de los mercados de trabajo y para la óptima eficiencia de las emptesas. Además, contempla mucha de la legislación protectora promulgada en los años setenta como una barrera para la eficacia empresarial, especialmente en la pequeña empresa. 
En consecuencia, ha revocado o debilitado muchas de las leyes aprobadas en esos años. Varios derechos legales individuales, especialmente los de protección contra el despido injusto, se han debilitado durante los años ochenta, y algunas categorías de trabajadores (a tiempo parcial, trabajadores a domicilio, etc.) nunca los han tenido (Dickens, 1988). Además de esta tendencia a la destegularización, nos encontramos con la opinión del gobierno de que estas protecciones a los puestos de trabajo colocan cargas inaceptables en las compañías, especialmente en la pequeña empresa. Se puede percibir el mismo ataque desregulatorio en la persistente oposición del gobierno británico a los intentos de la Comunidad Europea para promulgar normas mínimas de protección para los trabajadores temporales y a tiempo parcial, y en su hostilidad hacia las propuestas de democracia industrial y derecho a la información.

Quizá los cambios legales más importantes han sido los que afectan el derecho de los sindicatos a ir a la huelga sin incurrir en castigos legales 0 financieros. Las Leyes de Empleo de 1980, 1982 y 1988, y la Ley de Sindicatos de 1984 han limitado la libertad de los sindicatos para ir a la huelga legal confinándola al lugar de trabajo de los empleados, restringiendo las razones por las cuales se puede ir a la huelga legal y exigiendo votaciones secretas de los participantes antes de que la huelga sea autorizada.

La existencia de estas restricciones legales, combinada con la creciente evidencia de que los empresarios pueden utilizarlas de manera eficaz, a menudo costando a los sindicatos grandes cantidades de dinero si no cumplen la ley, han debilitado el poder de negociación colectiva de los sindicatos. Los cambios legales han hecho que les sea más dificil el reclutamiento y la organización en sectores desorganizados de la economía, tales como el sector terciario, y esto es de particular importancia a la luz de los cambios en el mercado laboral resumidos más arriba.

\section{El Estado}

Durante los años setenta, el enfoque de los gobiernos tanto conservadores como laboristas hacia los sindicatos y los empresarios había consistido en ampliar las estructuras corporativas tripartitas de gestión económica, usán* dolas como base para buscar el acuerdo con los sindicatos en las políticas de restricciones salariales. Este tipo de actitudes incrementó la autoridad política de los sindicatos y su influencia en asuntos de política económica. Al mismo tiempo, el Estado continuaba apoyando la ampliación de la nego. ciación colectiva, tanto por medio de la ley (véase más arriba), como a través del apoyo directo a la misma en el constantemente creciente sector 
público. Tanto el intento de influir el proceso de negociación salarial como el crecimiento del sector público reflejaban el compromiso del Estado con una política económica con un fuerte acento keynesiano. A últimos de los años setenta surgieron problemas económicos a causa del fracaso en la restricción de salarios $\mathrm{y}$, más significativamente, debido a la creciente preocupación por el ritmo del crecimiento del gasto público; sin embargo, la reacción del gobierno laborista de la época fue intentar controlarlo por medio de la ampliación de los convenios corporatistas.

Al igual que con la política legislativa, esto cambió radicalmente con la elección de Margaret Thatcher en 1979. El compromiso del nuevo gobierno con políticas monetaristas redujo su interés en el proceso de negociación salarial y centró su atención en factores del lado de la oferta, en los que consideraba que los sindicatos en particular dañaban el funcionamiento eficaz del mercado de trabajo. Al mismo tiempo, intentó reducir el gasto pú. blico de una manera rápida por medio de tecortes drásticos $\mathrm{y}$, más dramáticamente, por medio de la privatización a gran escala de corporaciones públicas, telecomunicaciones y gas, entre otras; y la electricidad y el agua que pronto se añadirían a la lista.

Las estructuras tripartitas/corporatistas del plan económico fueton abolidas o recortadas. Quizás el caso más significativo ha sido la sustitución de la Comisión de Servicios de Mano de Obra, que tenía la responsabilidad general de la política de formación, por una Agencia de Formación privatizada sin representación efectiva de los sindicatos. Se ha anulado la influencia política de los sindicatos, por lo menos esto es lo que se deduce de la participación sindical en instituciones tripartitas eficaces.

\section{COMPORTAMIENTO DEL EMPRESARIO}

El comportamiento del empresario en los años ochenta ha cambiado. En los años setenta, los empresatios, tanto en el sector privado como en el público, se habian convencido en general de que la negociación colectiva iba a crecer, y que la respuesta más eficaz por su parte consistía en crear procedimientos cada vez más formales que regularizaran los procesos de tomas de decisión en las relaciones industriales. La legislación ayudó en asuntos tales como el despido iniusto y la discriminación, en los que se daba gran importancia a la corrección de los procedimientos. A pesar de estos avances, las relaciones industriales siguieron basándose en procedimientos defensivos y $a b$ boc, conservando un grado de informalidad que sorprendería al público americano y europeo (Sisson \& Brown, 1983). 
Durante los años ochenta se empezó a ver que los enfoques de los empresarios estaban experimentando cambios fundamentales respecto a la gestión de la mano de obra. Varios factores habían contribuido a esto.

En primer lugar, se sugirió que la experiencia de los años setenta había demostrado a los empresarios la ineficacia de la negociación colectiva como mecanismo para una tápida introducción de transformaciones. Las cambiantes circunstancias de mercado de los años ochenta ya no conducían a negociar las transformaciones; la supervivencia economica dependía de la introducción ágil de medidas duras - sobre nueva tecnología, pérdida del puesto de trabajo y reorganización del empleo- y eran los directores los que debían tomar las decisiones y llevarlas a cabo.

En segundo lugar, la reducción del tamaño de los establecimientos permitiría a los empresarios desarrollar métodos más individualizados de dirección de personal, que en consecuencia darían menos peso específico a los procesos colectivos.

En tercer lugar, la debilidad de los sindicatos, motivada por el desempleo y la legislación, permitiría a los empresatios recobrar la iniciativa y desarrollar enfoques estratégicos a largo plazo para dirigir al personal.

En cuarto lugar, la Ilegada de las empresas japonesas a Gran Bretaña y su enfoque característico en cuanto a la gestión, combinado con su obvio éxito comercial, Llevó a tnuchas compañías británicas a pensar en emularlas.

En tesumen, según esta opinión, los años ochenta proporcionaron a los empresarios la oportunidad y el motivo pata alejarse de políticas defensivas basadas en la negociación colectiva para acercarse a políticas ofensivas basadas en técnicas más individualizadas (véase Hawksworth, 1984).

Para este razonamiento era vital la opinión que el fracaso económico de los años sesenta y setenta fue, en parte, el resultado de que la dirección cedieta sus prertogativas directivas a la negociación colectiva. El éxito en los ochenta sólo podía alcanzarse si la dirección recobraba y reafirmaba su «de. recho a dirigir" (para una clara afirmación de este punto en una importante empresa británica, véase Edwardes, 1983). De hecho, en muchas empresas se han reafirmado las prerrogativas de la dirección mediante un mayor con* trol y una disciplina trás dura; y los trabajadores, formales e informales -o el sindicato-, que controlaban los puestos de trabajo, se han debilitado o eliminado (aunque algunas investigaciones muestran que hay una tendencia al retorno a la situación anterior). Muchos de los cambios se han introdu. cido sin ningún tipo de consulta o negociación. La pregunta es si esta estrategia ha llevado a una mejora de la productividad. Algunos autores afirman que sí, mientras otros están igualmente seguros de que no hay evidencia que apoye esta conclusión. (Para una discusión completa del tema véase Nolan \& Marginson, 1988). Sin embargo, el debate es crucial, porque de él 
dependen a largo plazo los métodos que la dirección adopte con respecto a los sindicatos y a la negociación colectiva.

\section{El SECTOR PÚBLICO}

El sector público quizá nos ofrece la evidencia más dramática del cambio. El énfasis de la dirección en los años sesenta y setenta en políticas de evitación de conflictos, a través de una amplia consulta y negociación para buscat el consenso con los sindicatos, se ha sustituido por un enfoque mucho más duro y dispuesto a la confrontación (véase Fetner, 1985, 1988).

En muchas partes del sector público, la dirección ha debilitado la ma. quinaria de negociación colectiva ya existente, rechazando el uso del arbitraje (una antigua práctica para la solución de conflictos en el sector público) y se ha vuelto cada vez más a una implementación unilateral de las transfor. maciones. Estos cambios han sido la respuesta tanto a los estrechos controles financieros (tales como la retirada de las subvenciones estatales) como a la intervención política. Esta última ha adoptado la forma de hacer depender las subvenciones estatales de la consecución de cambios específicos en la práctica laboral, y de apoyar a la dirección para que se enfrente a los sindicatos. Se ha sugerido que estas estrategias de importantes reformas sólo podrían haber sido posibles en el sector estatal, ya que ningún empresario en el sector privado se habria arriesgado a tal política de enfrentamiento. Ciertamente, las compañías estatales tales como la British Steel (aceros) o la British Leyland (ptoducción de automóviles) van por delante en cuanto a recuperar el poder de la dirección y debilitar el de los sindicatos.

$\mathrm{El}$ ataque de la política gubetnamental se ha dirigido hacia la privatización de los fondos y servicios del sector público. La venta de industrias na. cionalizadas al sector privado ha tenido lugar a gran escala durante la última década. La intención ha sido restablecer la disciplina de mercado y afrontar el miedo a la bancartota; en opinión del gobierno, la ausencia de estos facto. res contribuyó a los bajos niveles de cumplimiento y servicios al cliente.

Se ha asociado la privatización con la descentralización de la toma de decisiones por medio de la creación de nuevas estructuras de división o regio. nales, y con la degradación de la negociación colectiva. Sin embargo, en la práctica, el impacto de estos cambios ha vatiado. En British Transport Ho. tels, que anteriormente poseía la British Rail (ferrocarriles británicos), la privatización ha llevado a un rápido colapso de la organización sindical y de la negociación colectiva (los sindicatos siempre han tenido problemas para organizar el sector hotelero privado). En cambio, en la British Telecom, la afliación sindical se ha acercado al 100 por cien, y hay alguna evidencia 
de que la dirección sigue comprometida a conservar partes significativas de la maquinaria de negociación colectiva.

La política de relaciones industriales en el sector público también ha sido influida por consideraciones políticas más amplias. El gobierno ha tomado la determinación de evitar las derrotas infligidas a los gobiernos laboristas y conservadores por la acción de los sindicatos del sector público durante los años setenta. Algunos comentaristas han sugetido que las tácticas de los empresarios y del gobierno durante las huelgas mineras de $1984-85$ y la disputa de «listas flexibles» sobre los ferrocarriles en 1982, se han debido en gran parte al deseo del gobierno de demostrar públicamente su habilidad para enfrentarse y derrotar a lo que veía como obstruccionismo de los sindicatos del sector público (véase Ferner, 1985).

Aun con estos cambios, hay estabilidad en el modelo de relaciones in. dustriales en el sector público. La afiliación de los sindicatos sigue siendo alta en las restantes corporaciones del sector público, en los servicios y en varias corporaciones privatizadas. A pesar de un cierto grado de retraimiento por parte de la dirección de la negociación colectiva y de la consulta, éstas continúan bien desarrolladas; de hecho, hay alguna evidencia de que habiendo intentado enfoques más unilaterales, los directores están volviendo a las reconocidas ventajas del reconocimiento de sindicatos y de la negociación colectiva.

No hay evidencias de una búsqueda extendida por parte de la dirección de estrategias de personal basadas en técnicas antisindicales, aunque no ha habido demasiado reconocimiento de los sindicatos por parte de los altos cargos directivos y sí ha habido un uso limitado de formas no sindicales de comunicación con los trabajadores (ver más adelante).

\section{EL SECTOR PRIVADO}

Aquí la imagen es muy variada. La evidencia de Ia investigación sugiere una reducción en el alcance del reconocimiento de los sindicatos en el sector manufactureto, que es en parte el resultado del aumento en el sector de servicios privados (Millward \& Stevens, 1986). A pesar de algunas quejas, no hay evidencia convincente de ataques importantes a los sindicatos. El estudio de casos sugiere que las empresas que se enfrentaron a los más severos efectos de la recesión a principios de los años ochenta eran las más combativas en sus relaciones con los sindicatos, a menudo llevando a cabo cambios sin ningún tipo de consulta o negociación. Pero en la mayor parte del sector privado, las estructuras formales de reconocimiento de los sindicatos y la negociación colectiva se han mantenido. 
Los cambios más importantes se han producido en fábricas nuevas, especialmente en industrias de alta tecnología, donde algunas compañias se están negando totalment a reconocer a los sindicatos o están experimentando con paquetes de medidas que otorgan a los sindicatos un papel mucho menos significativo (véase más adelante).

Sin embargo, la imagen no es tan estática como este breve tesumen podría sugerir. La evidencia de la investigación (Edwards, 1987) nos informa del descubrimiento aparentemente contradictorio de que los directores están empleando más tiempo en temas relacionados con el personal, pero telativamente menos tiempo que antes en temas de relaciones industriales que tengan que ver con los sindicatos. La imagen que parece emerger es que muchas empresas, insatisfechas con las fórmulas de relaciones industriales existentes, están intentando desarrollar nuevos métodos de dirección de personal, mientras que, al mismo tiempo, conservan la estructura de los antiguos enfoques, por si acaso los nuevos sistemas no funcionaran.

Se puede afirmar que en los años ochenta la atención de los empresarios: se ha centrado más en la introducción de cambios a nivel de empleo, organización del trabajo y nueva tecnología, que en las condiciones de trabajo y los salarios de los trabajadores. Dos estudios sobre la industria manufacturera en los años ochenta mostraton que más del 80 por ciento de las empresas había introducido cambios inportantes, durante los cinco años antetiores, en las disposiciones de trabajo o en mecanismos que sirvieran para aumentar la eficacia de la utilización de la mano de obra. Estos incluían la introducción de nueva tecnología, trabajo flexible y medidas para aumentar la eficacia del equipamiento ya existente (Edwards, 1987; Batsone, 1984). También se deduce de estos estudios que, aunque los directores: consideraran importantes las relaciones con los trabajadores para el manejo de los cambios, prestaron relativamente poca atención a las estructuras con* vencionales de negociación colectiva en su introducción. Generalmente, los directores han tenido interés en reaffrmar su derecho unilateral en el control de los puestos de trabajo y de la organización del trabajo, y han intentado sacar partido de la relativa debilidad de los sindicatos en los años ochenta para, así, tecobrar ese control. Muchos de estos cambios se han introducido unilateralmente. La opinión de la mayoría de los analistas es que lo harr conseguido, y que el sindicalismo ya no es un factor que impida la utilización óptima del personal y de la maquinaria. (Debería hacerse notar que el alcance de la influencia de los sindicatos en la organización del trabajo y factores relacionados con ella en los años setenta puede haber sido menos importante de lo que se creyó.) Sin embarjo, muchos directores actúan ahora como si el poder de los sindicatos hubiera sido dominado y como si eso hubiera contribuido a mejorar la situación. 
En lo que se tefiete a salarios y condiciones de trabajo la imagen es ligeramente distinta. Generalmente, los empresarios han continuado regulándolos a través de la maquinaria establecida por la negociación colectiva, incluso hasta el punto de pasar por el ritual de la negociación cuando la debilidad de los sindicatos lo hacía innecesario (Chadwick, 1983).

Para la mayoría de trabajadores del sector privado, la paga se ha mantenido por delante de la inflación, durante los años ochenta, aunque debería mencionarse que, en parte, esta situación era un reflejo del desempleo a gran escala de los trabajadores menos cualificados y peor pagados. Las diferencias entre salarios han aumentado (los mejor pagados han recibido mayores aumentos que los peor pagados, reflejando en parte la grave escasez de personal cualificado y técnicos). Esto podtía sugerir la continuación de un poderoso papel de la negociación colectiva respecto a los salarios, sugerencia que parece confirmarse con la observación de que los diferenciales entre salarios negociados sindicalmente y los que no lo han sido han aumentado notablemente (Metcalf \& Nickell, 1985).

Con todo, los mismos empresarios no atribuyen los aumentos a la negociación con los sindicatos; y ven la rentabilidad de las empresas como el factor más significativo que pueda afectar las negociaciones de salarios de los años ochenta. Debetía hacerse notar, sin embargo, que al mismo tiempo muchos empresarios han estado buscando métodos más individualistas de incentivos, incluyendo pagas por méritos y otras formas de remuneración relacionadas con el cumplimiento, además de planes para que los empleados obtengan acciones de la empresa. Éstos se tratan normalmente fuera de los mecanismos de la negociación colectiva, incluso en empresas que normalmente fijan el salario a través de la negociación con los sindicatos. A pesar del entusiasmo hacia estos enfoques entre muchos directores, las investigaciones sugieren que todavía es demasiado pronto para establecer conclusiones sobre sus efectos.

Sin embargo, como ya se ha mencionado anteriormente, se ha asociado la mayor parte del desarrollo de las relaciones industriales con el manejo de los cambios surgidos en el trabajo relacionado con la producción. En este caso, la mayor fuente de inspiración proviene de las actividades de las compañias multinacionales japonesas que han empezado a fabricar en Gran Bretaña. Muchas de estas compañías han desarrollado un enfoque común con respecto a las relaciones industriales, que es considerado como novedoso y de gran éxito. El enfoque japonés, basado en la retórica de la participación de los trabajadores y en el compromiso y «armonización» de los términos y condiciones de empleo entre los administrativos y los obreros, reafirma firmemente, sin embargo, las prerrogativas de la dirección. El compromiso del trabajador se concreta de una manera definida por la dirección y en asuntos de 
su eleción. Se afirma que el énfasis de las empresas japonesas se encuentra en la relación entre la empresa y el trabajador individual, y es esta individualización de las relaciones con los trabajadores to que proporciona el rasgo distintivo a estas iniciativas. La comunicación, la participación y las técnicas de compromiso toman como punto de partida al trabajador individual más que al colectivo.

Por lo tanto, en estas empresas japonesas, donde se reconoce a los sindicatos, éstos tienen un papel muy limitado. Típicamente las compañías japonesas insisten en reconocer un solo sindicato («acuerdos de sindicato único») por considerar que ello intensifica la flexibilidad, obteniéndose acuerdos con los sindicatos a través de un particular mecanismo de solución de los conflictos, conocido como «el arbitraje del péndulo». En el arbitraje del pén. dulo, el papel de un árbitto independiente se limita a fallar a favor de la demanda del trabajador o de la oferta del empresario; y no se permite buscar un tesultado de compromiso entre las dos posiciones. Los defensores de esta forma de arbitraje indican que lleva a la moderación y a la mesura por ambas partes. Según sus detractores, se inclina a favor del empresario, especialmente cuando se conjuga con otra catacterística común de estos acuerdos, la llamada «cláustrla contra la huelga». El título se presta a malas interpretaciones, ya que, en Gran Bretaña, ningún aspecto de la negociación colectiva puede obligar legalmente, a menos que ambas partes estén de acuerdo. Lo que estas cláusulas consiguen es dejar claro que, en caso de que Ios trabajadores vayan a la huelga, el sindicato al que pertenecen no les apoyará si han firmado la cláusuia. Por lo tanto, el aspecto colectivo de estos acuerdos «japoneses» ejerce presión en pro de la paz industrial y la producción continuada.

A pesar del interés despertado por estos enfoques, su efecto práctico es hasta ahora pequeño. En 1986 se estimó que alrededor de 9.000 trabajadores, de los cuales 5.000 estaban afiliados, quedaban cubiertos por aspectos que contemplaban todos los puntos mencionados. En 1987, quizás afectó a otros 2.000 trabajadores (Oliver \& Wilkinson, 1988). Sin embargo, ha proporcionado un modelo de política de personal que varias de las empresas británicas importantes han tratado de emular.

Mientras que relativamente pocas empresas británicas han intentado adoptar todas las características del enfoque japonés, muchas han experimentado con uno o más elementos de esas medidas, en particular aquellas que reflejan un nuevo interés en el individuo en contraposición a las relaciones con los trabajadores como colectivo. Algunos estudios confirman el au. mento de los mecanismos de consulta durante los años ochenta, los cuales incluyen informes habituales de los directores a los trabajadores (Millward \& Stevens, 1988). Muchas empresas también han intentado introducir círcu- 
los de calidad, aunque la evidencia sugiere que muchos fracasan a menudo debido a la hostilidad por parte de los directores, que temen que los círculos de calidad socaven la autoridad jerárquica de la dirección (IRRR, 1988). A pesar de que los recursos de la dirección se han dedicado al desarrollo de nuevas formas de participación y compromiso, es difícil creer que formen parte de una estrategia general. Oliver y Wilkinson señalan que uno de los problemas básicos de las empresas británicas con sindicatos establecidos es que:

«Cualquier postura independiente y potencialmente contraria es antite. tica a la organización de estilo japonés, y la mayoría de las compañías que los emulan se encuentran con varios sindicatos independientes cuyo objetivo es la protección y el avance de los intereses de grupos ocupacionales concretos.»

Así, muchas de las empresas británicas sindicalizadas del sector privado se enfrentan a este dilema. No están seguras de las ventajas de desmantelar totalmente los sindicatos ya existentes y los sistemas de negociación colectiva como se requiere en el modelo japonés completo. Sin embargo, les atrae el aparente éxito de la fórmula japonesa. Su respuesta, por lo general, ha consistido en añadir elementos del nuevo enfoque a las estructuras del antiguo. De todas maneras, dada la incompatibilidad básica de los dos sistemas, especialmente en lo que se refiere a la importancia que se da al papel de los sindicatos, se puede decir que es un enfoque inestable.

\section{LOS SINDICATOS}

\section{LOS SINDICATOS Y EL MERCADO DE TRABAJO}

Los sindicatos han sufrido un duro golpe a causa del desempleo y los cambios en la composición industrial y ocupacional de la fuerza de trabajo. La recesion ha afectado más intensamente a aquellos sectores en los que la afliación sindical había sido tradicionalmente más fuerte (de manera más notable en la industria manufacturera) y en las industrias extractoras del Estado e industrias primatias (carbón, acero), donde los efectos de la recesión han sido magnificados por políticas del gobierno destinadas a reducir el gasto público y desarrollar fuentes alternativas de suministro. Las tendencias generales de afiliación sindical pueden verse en la tabla 2.

Dicha tabla muestra el colapso de la afiliación sindical desde 1979 en su proporción sobre la población activa («densidad sindical»). Sin embargo, este 


\section{TABLA 2}

Densidad sindical en Gran Bretaña y el Reino Unido, 1948-1987

\begin{tabular}{|c|c|c|c|c|}
\hline & 1948 & 1968 & 1979 & 1987 \\
\hline Densidad total sindical en el Reino Unido ... & 45,2 & 44,0 & 54,4 & 41,9 (a) \\
\hline Densidad total sindical en Gran Bretaña ...... & 45,0 & 42,7 & 53,2 & \\
\hline Densidad sindical masculina en Gran Bretaña & 55,4 & 51,4 & 63,1 & \\
\hline Densidad sindical femenina en Gran Bretaña & 24,3 & 27,5 & 39,0 & \\
\hline $\begin{array}{l}\text { Densidad sindical entre los obreros en Gran } \\
\text { Bretaña } \ldots \ldots \ldots \ldots \ldots \ldots \ldots \ldots \ldots \ldots \ldots \ldots \ldots \ldots \ldots \ldots \ldots \ldots \ldots \ldots \ldots \ldots \\
\text { Densidad sindical entre los administrativos en }\end{array}$ & 50,3 & 49,8 & 62,5 & \\
\hline 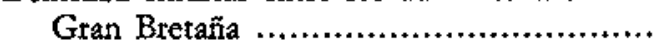 & 33,0 & 32,6 & 43,6 & \\
\hline
\end{tabular}

FuenIF: G. S. Bain y R. J. Price, kUnion Growth», G. S. Bain (ed)., Industriat Relations in Britain (Oxford, Blackwelt, 1983), Tablas 1.t, 1.2 y 1.3 .

(a): Las ciftas de afliacion sindical en 1987 son estimativas. La afiliación total, incluyendo la afiliación a las TUC $(9.243 .297)$ incrementaba ésta en tan 14,018 por ciento en 1986. De ahí que las cifras de afliación de las TUC en $1987(9.126 .911)$ se aumenten en un 14,01 por ciento para dar una cifra total de afiliación sindical de 10.406.321.

descenso general oculta variaciones importantes, de las que se puede obtener alguna información observando lo que les ha ocurrido a los sindicatos individuales.

Estas cifras reflejan claramente el colapso del empleo en la industria minera y la manufacturera -especialmente mecánica-, de donde obtenían mucha de su afiliación los sindicatos de Mecánicos y Electricistas, así como también los de Transportes y Trabajadores en general. Esto ha significado un índice más bajo de descenso en los servicios públicos y un aumento en los administrativos de los sectores técnico y eléctrico de las manufacturas, así como en los sectores de banca y finanzas. Así, los grados de afiliación sindical parecen descender y aumentar con los cambios en el empleo de un modo telativamente paralelo. De manera similar, la proporción de mujeres afliadas a los sindicatos ha aumentado de manera lenta pero constante, alcanzando el 35,9 por ciento de la afiliación sindical total en 1986, otra vez más o menos en línea cor los cambios en el mercado de trabajo.

En los años ochenta, vatios sindicatos acuciados por la disminución de afiliados han empezado a desarrollar nuevos sistemas para su reclutamiento y conservación. Éstos han tomado dos formas principales fuera de la negociación colectiva. En primer lugar, han ampliado los servicios que ofrecían a sus afiliados. Éstos incluyen servicios de pensiones, seguros personales y otros servicios financietos, y asistencia legal en asuntos que no sean de trabajo, incluyendo aspectos como comprar una casa y hacer un testamento 
Afiliación en sindicatos individuales, 1979-1986 (en \%)

Sindicato Nacional de Mineros ...................................... $\quad-72$

Sindicato de Transportes y Trabajadores en general .................. -34

Sindicato de Mecánicos Unidos ..................................... -34

Sindicato de Electrónica, Electricistas, Telecomunicaciones y Lam. pistería ........................................................

Sindicato Genetal Municipal de Caldereros y afines ................. -16

Sindicato Nacional de Empleados Públicos …....................... -5

Asociación Nacional Local de Empleados del Gobierno ............... $\quad-0,4$

Personal Técnico Administrativo y de Supetvisión ................... +20

Sindicato de Seguros, Banca y Finanzas ............................ +21

(TUC, 1988). Los sindicatos también están investigando la posibilidad de hacer sus propias tarjetas de crédito. En muchas de estas áreas se han ayudado con la fundación de su propio banco, el Unity Trust Bank, fundado a principios de los años ochenta. Se espera que la existencia de estos servicios haga más atractiva la afiliación a los ya affliados, y que dé a los que aún no lo están una razón individual para inscribirse. (Algunos críticos están preocupados, ya que esto podría llevar a que los sindicatos compitieran entre ellos según los beneficios que puedan ofrecer.)

Además de estos servicios, muchos de los cuales atraen más a afiliados relativamente acomodados, algunos sindicatos, explícitamente, se han impuesto la tarea de hacerse más atractivos y adecuados a grupos de trabajadores que, hasta ahora, habian sido ignorados o marginados por los sindicatos, como son: mujeres, trabajadores a tiempo parcial y trabajadores del creciente sector de servicios terciarios. Para muchos, éstas son categorías que coinciden.

Uno de los más fervientes defensores del nuevo enfoque es John Edmonds, secretario general de uno de los más grandes sindicatos británicos, el Sindicato General Municipal de Calderetos (GMB). Es él quien ha sugerido que para muchos de estos trabajadores los sindicatos eran y continúan siendo poco atractivos, ya que la naturaleza de su trabajo era tal que la negociación colectiva, pensada para trabajadores pertenecientes a organizaciones colectivas estables y poderosas, eza totalmente imposible. En consecuen. cia, los sindicatos se han visto en la obligación de desarrollar un enfoque que no ofreciera la negociación colectiva como única estrategia. Edmonds sugiere que los sindicatos necesitan desarrollar una abierta campaña, que abogue por el desarrollo de regulaciones legales que sirvan pata proteger las condiciones 
y términos básicos de los trabaịadores más débiles y que tienen que actuar como garantes del cumplimiento de la ley con respecto a los derechos legales de este tipo de trabajadotes (Edmonds, 1988).

Varios sindicatos están tomando iniciativas pata animar la afiliación femenina. Éstas incluyen campañas en favor de la prevención del cáncer y servicios de guardería infantil. También están intentando reemplazar su antigua hostilidad hacia el trabajo a tiempo parcial por un enfoque que lo contemple como de particular valor para ciertos grupos de afiliados, especialmente mujeres, que quizás no puedan hacer jornada completa.

Estas iniciativas están todavía en sus comienzos y muchos sindicatos tienen una dura tarea para convencer a sus afiliados y cuadros de la necesidad de adaptarse a las nuevas circunstancias. Pero sindicatos tales como el de Transportes y Trabajadores en general creen que los recientes aumentos en su afliación podrían indicar que la estrategia empieza a funcionat.

\section{LOS SINDICATOS, EL EsTAdO Y LA LEY}

Los sindicatos han respondido con una mezcla de indignación e incertidumbre a su cada vez mayor exclusión al acceso al gobierno y a los órganos de decisión política. Habiéndose acostumbrado a su implicación creciente en instituciones tripartitas, los líderes sindicales dieron por hecho que esta situación continuaría. Enfrentados a un gobierno que no ocultaba su antipatía hacia la planificación y regulación centrales, ni su convicción de que los sindicatos no tenían un lugar legítimo en la formación de políticas económicas e industriales, los sindicatos estaban simplemente anonadados. Una legitimidad política en aumento había intensificado su estatus y la percepción que ellos mismos tenían de su importancia política; encarados con la negación de este punto de vista, no reaccionaron. Como ha dicho John McIlroy:

"La reacción de los sindicatos al thatcherismo se ha reducido hasta convertirse en una afirmación de su derecho a tener un papel clave en los meandros del poder. Han incitado oposición a las políticas gubernamentales en un intento de presionar hacia el cambio.»

No se puede afrmar que esta política baya tenido éxito. Por ejemplo, cuando después de muchos debates internos los sindicatos se retiraron de la participación en la iniciativa del gobierno para formación de empleo, sosteniendo que se trataba de una formación deficiente basada en la obligación y la explotación, el gobierno se limitó a abolir la Comisión tripartita de Servicios de Mano de Obra y a reemplazarla por una Agencia de Formación de carác. 
ter privado, de esta manera se excluía completamente a los sindicatos del papel que pudieran jugar en cualquier aspecto de la política nacional de formación. Antes de eso (en 1984) los sindicatos se habían retirado del Consejo Nacional de Desarrollo Económico como protesta a la prohibición gubernamental de la afiliación en sindicatos pata ciettos trabajadores implicados en empleos de seguridad.

A principios de los años ochenta, el Congreso de las Trade Unions organizó una serie de actos de protesta a nivel nacional contra la política gubernamental; los más notables fueron las «Marchas del Pueblo para el Empleo" contra el alto índice de paro. Pero el fracaso de los actos para con la política del gobierno, combinado con la segunda victoria de Thatcher en las elecciones generales de 1983 llevó a las TUC a abandonar este tipo de tácticas. Esto ha Ilevado a la emergencia de lo que a veces se ha llamado el «Nuevo Realismo», basado en un enfoque conciliatorio para con el gobierno, más que en un enfoque antagonista. No hay evidencia de que este enfoque haya tenido algún tipo de éxito.

Lo mismo se puede decir de la reacción de los sindicatos a las sucesivas leyes que han reducido dramáticamente el derecho sindical a la huelga y restado muchos de los poderes y protecciones que abarcaban a sindicatos y trabajadores en los años setenta. En $1982 \mathrm{el}$ movimiento sindical acotdó un paquete de propuestas destinado a mostrar su oposición hacia las nuevas leyes. En particular acudieron a la autoridad del Consejo General de las TUC cuando un sindicato que se enfrentaba a la acción legal le pidió ayuda para:

«acción coordinada con otros sindicatos afiliados en apoyo al sindicato en dificultades, incluyendo, si es necesario, declarar la huelga contra el empresario en cuestión, o más allá» (TUC, 1982, en McIlroy, 1988).

En la práctica, las TUC nunca pudieron concretar esta política y, en 1984, habiendo sido testigo del daño que se podía hacer a los sindicatos con las nuevas leyes, la posición de las TUC había pasado de apoyar la oposición a aconsejar a los sindicatos que cumplieran la ley. Esto también formaba parte del «Nuevo Realismo».

Inevitablemente, los problemas creados a los sindicatos por el abandono gubernamental de los acuerdos tripartitos y por su programa legislativo, han intensificado el interés de los líderes sindicales en trabajar para asegurar el retorno de un gobierno laborista. En esto tampoco han tenido éxito, como muestra la siguiente tabla: 
TABLA 4

Cómo votaron los sindicalistas (\%)

\begin{tabular}{|c|c|c|c|c|c|c|c|c|}
\hline \multirow[b]{2}{*}{ Partido } & \multirow[b]{2}{*}{1964} & \multirow[b]{2}{*}{1966} & \multirow[b]{2}{*}{1970} & \multirow{2}{*}{$\frac{\text { febrero }}{1974}$} & \multicolumn{4}{|l|}{ octubre } \\
\hline & & & & & 1974 & 1979 & 1983 & 1987 \\
\hline Laborista $\ldots . . . \ldots \ldots \ldots . .$. & 73 & 71 & 66 & 55 & 55 & 51 & 39 & 42 \\
\hline Conservador...$\ldots \ldots \ldots$ & 22 & 25 & 28 & 30 & 23 & 33 & 31 & 26 \\
\hline Otros $\ldots \ldots \ldots \ldots \ldots \ldots$ & 5 & 4 & 6 & 15 & 16 & 13 & 30 & 26 \\
\hline
\end{tabular}

Fuenre: Mcliroy, 1988.

El aumento del apoyo electoral de los afiliados sindicales al Partido Consetvador en 1979, y el fracaso del apoyo al Partido Labotista en 1983 y 1987 , se consideran por algunos analistas como el punto de tuptura del entendimiento electoral que existía, tácitamente, entre los sindicatos y el Partido Laborista, según el cual a cambio de la aprobación por las TUC de los programas electorales, los sindicatos garantizaban el compromiso electoral de sus afiliados para con el Partido Laborista. Las cifras han llevado a algunos antiguos líderes sindicales a la conclusión de que para aumentar las oportunidades de éxito electoral de los laboristas debe haber una debilitación de las relaciones formales entre los sindicatos y el mencionado partido, ya que los votantes pueden ser disuadidos de votar al «partido de los sindicatos».

La única señal esperanzadora para los sindicatos Ilegó en 1985 y 1986. La Ley de Sindicatos de 1984 pedfa, entre otras cosas, que todos los sindicatos que operasen con un sistema de «fondos políticos» hicieran votar a sus militantes el mantenimiento de los mismos. Los sindicatos utilizan los «fondos políticos» para llevar a cabo cierto tipo de actividades políticas, incluyendo especialmente la afiliación al Partido Laborista. El gobierno, y muchos otros que tenían en mente el fracaso del apoyo de los afiliados sindicales a los laboristas, predijo que los sindicatos perderian muchos de estos votos y que se verian forzados a desafiliarse del Partido Laborista. De hecho (véase Blackwell \& Terry, 1987), los resultados de la votación apoyaron ampliamente la retención de los fondos, y varios sindicatos votaron su establecimiento por primera vez en Ia historia. Sin embargo, cualquier esperanza de que estos resultados indicaran un retorno del apoyo a los laboristas por parte de los afiliados a los sindicatos fue refutada por los resultados de las elecciones generales de 1987. 


\section{LOS SINDICATOS Y LOS PATRONES}

\section{El sector público}

Los sindicatos del sector público tienen la reputación de ser organizaciones moderadas, con una estructura de poder centralizado que refleja la tradicional centralización de la negociación colectiva. Tanto ellos como sus líderes están acostumbrados a utilizar el consenso en el manejo de los temas de relaciones industriales, y de ir directamente a los representantes del go. bierno cuando surge algún asunto urgente.

Aunque este modelo estaba bajo tensión en los años setenta, una década en la que el conflicto industrial a gran escala reapareció en el sector público, se han conservado la mayor parte de las estructuras y enfoques tra dicionales.

Sin embargo, en los años ochenta los sindicatos se han enfrentado a cambios fundamentales mientras la rentabilidad sustituía al servicio público como criterio dominante; se perdieron muchos puestos de trabajo, se privatizaron y/o se desregularizaron amplias parcelas del sector público, se descentralizaton y reestructuraton las estructuras nacionales y tanto el gobierno como la dirección de las empresas marginaron a los sindicatos.

La respuesta de los sindicatos ha sido una mezcla de resistencia y conformidad. Los sindicatos del acero y del carbón organizaton importantes huelgas nacionales para protestar contra el cierre y la pérdida de puestos de trabajo. El sindicato de mineros en particular desarroiló un análisis económico de la industria del carbón en defensa de su posición, que marcaba un paso adelante en el pensamiento económico de los sindicatos (Glyn, 1984). Al final, ambos sindicatos fueron derrotados, el de los mineros después de la huelga más amarga y larga de Gran Bretaña en muchas décadas, durante la cual el Estado desplegó todos sus recursos para derrotar al sindicato. Para muchos la derrota de los mineros se consideró la evidencia de la determinanación del gobierno de reducir el poder de los sindicatos en el sector público.

Los sindicatos han intentado llevar a cabo campañas contra la privatización en la mayor parte del sector público y, aunque no hayan tenido éxito, éstas les han dado oportunidades. En este caso, a menudo han desarrollado alianzas con otros grupos (consumidores, ecologistas, iglesias, grupos de comunidad, etc.) que pueden tener sus propios motivos para preocuparse por la privatización.

Desde la privatización de la British Telecom, los sindicatos han obtenido algunas ventajas del fracaso de los niveles de servicio ofrecidos al público. En la British Rail, el metro de Londres y en otros sitios, los sindicatos han 
podido criticar la política de seguridad seguida por la dirección, sosteniendo que su deterioto está relacionado con la reducción de puestos de trabajo y otros medios de recorte de los costos. En esto los sindicatos han obtenido un mayor grado de apoyo por parte del público. El problema fundamental de los sindicatos ha sido su incapacidad de obtenet el apoyo general del público o de los afiliados en la batalla para que las industrias sigan perteneciendo al Estado. Esto ha llevado a algunas personas a sostener que los sindicatos han fallado al desarrollar y mantener durante largo tiempo argumentos políticos en favor de la nacionalización. Esto conlleva implicaciones obvias para el Partido Laborista, aunque el tema se encuentra fuera del alcance de este trabajo.

Los sindicatos del sector público se han reestructurado para adaptarse al cambio. Muchos se han descentralizado para igualar a la ditección, desarrollando nuevos niveles de organización regional. También ha habido algunas fusiones de sindicatos del sector público, afectando en particular a los funcionarios y a los sindicatos de telecomunicaciones (los dos sindicatos más grandes del gobierno local están discutiendo actualmente su fusión).

Tanto la estrategia sindical como su estructura se han visto profundamente afectadas por los recientes cambios. A pesar de ello, la densidad sindical en el sector público (o lo que queda de él) permanece alta, persisten las estructuras formales de la negociación colectiva, y el mantenimiento de niveles relativamente altos de acción industrial por parte de los sindicatos del sector público demuestran su continuado poder de recuperación. El caso de Correos es muy sintomático, pues ha pasado de ser una de las áreas menos problemáticas de las relaciones industriales a convertirse en una corporación que se presenta como una de las más proclives a la huelga en Gran Bretaña.

\section{El sector privado}

En los centros de trabajo, los sindicatos se han enfrentado a empresarios que, como se ha dicho antes, están interesados en cambiar la estructura y las instituciones de la negociación colectiva y las relaciones con el trabajador, pero que, en general, no están seguros de cómo hacerlo.

Los sindicatos en Gran Bretaña, y especialmente los del sector privado manufactureto, se han caracterizado tradicionalmente por ser organizaciones defensivas y reactivas, preocupadas por temas restringidos de salarios y condiciones de trabajo. Recientes investigaciones sugieren que, contrariamente a los estereotipos populares, los sindicatos Gran Bretaña raramente han obstruido la introducción de nueva tecnología, pérdida de puestos de traba. 
jo o reorganización de empleo, sino que han intentado obtener compensación financiera por tales transformaciones.

Esto no cambió en los años ochenta. Lo que cambió fue el alcance y la velocidad de la introducción de la nueva tecnología, de la pérdida de puestos de trabajo y de la reorganización del empleo, con el resultado de que la incapacidad histórica de los sindicatos para reaccionar ante estos temas adquitió un significado más dramático. Los sindicatos de los años ochenta no han sido capaces de resistir la pérdida de puestos de trabajo y otros cambios, ni de proporcionar la base para un desafío ideológico a las prioridades patronales. En su mayor parte han aceptado las definiciones de los problemas efectuadas por los empresarios $y$, en consecuencia, han consentido en sus soluciones. Para algunos comentaristas esto parece representar una seria deficiencia en la capacidad de los sindicatos para representar a sus afliados (Terry, de próxima aparición), pero para otros puede ser una táctica imprudente para los sindicatos el avanzar demasiado en el desarrollo de sus propias prioridades acerca del management.

La respuesta apropiada hacia el enfoque japonés sefialado anteriormente ha sido un importante tema de controversia sindical. Un sindicato, el Sindicato de Electricidad, Electrónica, Telecomunicaciones y Lampistería (EETPU), ha ido a la cabeza en cuanto a proponer el sindicato único y los acuerdos antihuelga. En su opinión, otra vez parte del "Nuevo Realismo», si estas condiciones son necesarias para obtener el reconocimiento de los empresarios, entonces deberían ser concedidas.

Otros sindicatos rechazan estas posiciones categóricamente, argumentan'do que las concesiones van demasiado lejos al negar algunas libertades básicas, tales como el derecho a la huelga. El agresivo método de reclutamiento del EETPU, basado en su predisposición a aceptar esos acuerdos, con com* pañías japonesas y no japonesas, culminó en su expulsión del Congreso de las Trade Unions en 1988. A pesar de ello, el EETPU persiste en afirmar, junto a muchos empresarios, que su punto de vista con respecto al sindicalismo en el sector privado es la única estrategia sindical aptopiada (véase Bassett, 1987). El Congreso de las Trade Unions se enfrenta a importantes problemas para encontrar una estrategia que preserve las libertades sindicales sin que los empresarios les deroguen su reconocimiento.

Los sindicatos también están teniendo problemas para adaptarse a los elementos del nuevo enfoque patronal hacia el personal, que implica cada vez más la no participación y compromiso con los sindicatos. Temen estar más y más marginados y fuera de contacto, y está claro que, por lo menos en algunas empresas, ésa es la intención explícita. Pero, al mismo tiempo, como ya bemos visto, muchas compañías conviven con sus sindicatos y por lo thenos mantienen la apariencia de una negociación colectiva normal de salatios 
y temas de condiciones de trabajo. Además, los sindicatos están sobrellevan. do una carga de injusticias individuales, como métodos de trabajo más intensivos y una disciplina más duta por parte de la dirección, que tienen su efecto. Algunas evidencias sugieren que, tanto para los trabajadores como para los empresatios, las realidades de continuidad son mayores que la impresión de cambio.

\section{CONCLUSIONES}

A pesar del alcance de los cambios desde 1979, parece que se han exagetado las pretensiones de su envergadura y su significación, por lo menos hasta ahora. El enfoque del zobierno y el clima económico han cambiado radicalmente, y sus efectos son reales e importantes. Pero la minuciosa revi. sión general que esto podtía haber ocasionado sólo parece haber tenido lu. gat a pequeña escala.

Los directivos, tanto del sector privado como del público, han intentado reducir la influencia de los sindicatos de varias maneras. Sin embargo, generalmente, no han actuado como si desearan eliminar los sindicatos ni la negociación colectiva, método defendido, por ejemplo, como necesario para la competitividad de la economía británica por el Instituto de Directores, otganización que suele ser escuchada por el gobierno. Muchos directores se han asustado de estos enfoques y han preferido la estabilidad de las instituciones conocidas. En muchos aspectos se podría decir que las tradiciones defensivas y ad boc se han conservado.

Hay que tener en cuenta un pequeño aspecto para comprender los profundos problemas de los sindicatos: han perdido varios millones de afiliados y mucha influencia industrial y política. Quizás el sentimiento de algunos líderes sindicales, que han pasado por lo peor de la recesión y han sobrevivido, sea demasiado complaciente. Los sindicatos tendrán que trabajar muy duro para recobrar el terreno perdido. Irónicamente, las encuestas de opinión pública muestran que el apoyo a los sindicatos es mucho mayor ahora de lo que ha sido en muchos años, aunque el significado de estos son. deos no está nada claro.

Los académicos británicos están empleando mucha energía para discutír si los sindicatos se están enfrentando a una crisis o no. Un comentarista hizo observar recientemente que se invertirían tres de las cuatro manifestaciones de crisis más frecuentemente citadas si el Partido Laborista ganara las elecciones. La observación muestra la importancia del contexto político (y éste no da pie al optimismo sindical). 
El mercado de trabajo es la otra gran incertidumbre. ¿Son los cambios poco importantes y cíclicos por naturaleza?, $o$, ¿son la evidencia de un cambio profundo e irreversible en la naturaleza de la producción, cuyas implicaciones cuestionarán todas las suposiciones sobre las relaciones industriales? No hay espacio aquí para una discusión detallada.

Se podría decir, simplemente, que los más convencidos de que no existe un cambio profundo tienden a apoyarse en las evidencias de las investigaciones sobre el conjunto de la economía, mientras que los que favorecen la tesis de cambio se apoyan en los estudios de casos individuales, principalmente en las industrias electrónicas y automovilísticas.

No hay una solución sencilla para estas diferencias, aunque el destino de los sindicatos, por lo menos, podría depender de qué predicción se elija, así como de la que tesulte ser correcta. 


\section{BIBLIOGRAFIA}

Bassett, P. (1987): Strike Free.

Batstone, E. (1984): Working Order: Workplace Industrial Relations over Two Decades.

Blackwell, R. y M. Terry (1987): «Analysing the Political Fund Ballots», Political Studies, XXXV.

Chadwick, M. (1983): «The Recession and Industrial Relations; a Factory Approach», Employes Relations, 5, núm. 5

Dickens, L. (1948): «Falling Through the Net: Employment Change and Worker Protection", Industrial Relations Journal, 19, núm. 2.

Edmonds, J. (1986): «New Wave Unions», Marxism Today (September).

Edwardes, M. (1983): Back from the Brink.

Edwards, P. K. (1987): Managing the Factory.

Ferner, A. (1988): Governments, Managers and Industrial Relations: Public Enterprises and their Political Environment.

- (1985): «Political Constraints and Management Strategies: the Case of Working Practices in British Rails, British Journal of Industrial Relations, 23 , núm. 1.

Glyn, A. (1984): The Economic Case Against Pit Closures.

Hawksworth, C. (1984): «Industrial Relations in the '80s: Whete Do the Unions Fit In?», Personnel Management (November).

IRRR (1988): "Quality Circle Impact Questioned by Study», Industrial Relations Review and Report, 430.

Keliy, J. (1988): Trade Unions and Socialist Politics.

McIlroy, J. (1988): Trade Unions in Britain Today.

MacInnes, J. (1987): Tbatcherism at Work.

Metcalf, D. y Nickell, S. (1985): «Jobs and Pay», Midland Bank Review.

Millward, N. y Stevens, M. (1986): Britisb Workplace Industrial Relations 19801984.

Nolan, P. y Marginson, P. (1988): «Skating on Thin Ice?: David Metcalf on Tra. de Unions and Productivity", Warwick Papers in Industrial Relations, número 22. 
«Papers»! Revista de Sociologia

Pollert, A. (1987): «The "Flexible Firm": a Model in Seatch of Reality", Warwick Papers in Industrial Relations, núm. 19.

Sisson, K. y Brown, W. (1983): «Industrial Relations in the Private Sector: Donovan Re-Visited», en G. S. Bain (ed.). Industrial Relations in Britain.

Terry, M. (de próxima publicación): «Recontextualising Shopfloor Industrial Relations», en Tailby, S. y Whitston, C. (eds.) Manufacturing Change.

TUC (1988): Services for Union Members. 